\title{
Fen ve Matematik Eğitiminde Baskın Kullanılmayan Beyin Bölgelerinin Değerlendirilmesi
}

Şirin İLKÖRÜCÜ, Yrd. Doç. Dr., Uludağ Üniversitesi Eğitim Fakültesi, ilkorucu@uludag.edu.tr,

http://orcid.org/0000-0003-6385

Çiğdem ARSLAN, Yrd. Doç. Dr., i̇stanbul Üniversitesi Hasan Ali Yücel Eğitim Fakültesi, arslanc@istanbul.edu.tr

Öz: Bu çalışmada fen ve matematik eğitiminde öğretmen adaylarının bütünsel beyin yaklaşımına göre baskın kullanılmayan beyin bölgelerinin tespit edilmesi hedeflenmiştir. Araştırma tarama modelindedir. Araştırmanın çalışma grubunu 70 Fen Bilgisi ve 63 Matematik öğretmen adayı oluşturmaktadır. Araştırmada adayların bütünsel beyin yaklaşımını belirlemek için beyin baskınlık ölçeği kullanılmıştır. Araştırma sonucunda fen ve matematik alanında eğitim gören öğretmen adaylarının baskın olmayan beyin bölgelerinin A ve D çeyrekleri yani beynin ön lobuyla ilişkili olduğu tespit edilmiştir. En çok kullanılan beyin çeyreği ise $C$ olmuştur. Ayrıca fen bilgisi ve matematik öğretmen adaylarının baskın olan ve olmayan beyin bölgelerinin benzer olması bu çalışmanın dikkat çekici bir bulgusudur.

Anahtar Kelimeler: Beyin baskınlığı, bütünsel beyin yaklaşımı, fen eğitimi, matematik eğitimi öğretmen eğitimi

\section{Assessment of Non-Dominant Brain Regions in Science and Mathematics Education}

\begin{abstract}
The present study was aimed to determine the brain dominance which are not used predominantly of prospective science and mathematics teachers'. The study was designed as a survey model. Data was obtained from questionnaire from the final year voluntary pre-service science teachers. The study was carried out with 70 prospective Science and 63 prospective Mathematics teachers. The brain dominance scale was used to determine the brain dominance of the prospective teachers in the study. As a result of the research, it has been determined that the prospective teachers who are studying in the field of science and mathematics are related to the non-dominant brain regions $A$ and $D$ quadrants, which are related with the frontal lobe of the brain. The most used brain region was C. It is also a remarkable finding of this study that the predominant and non-dominant brain regions of prospective science and mathematics teachers are similar.
\end{abstract}

Key Words: Brain dominance, mathematics education, science education, teacher education, whole brain theory. 


\section{GíRiş}

Beyin araştırmaları öğrenme ve öğretmeyi daha etkin kılan yaklaşımların ortaya çıkmasına imkân sağlayacak bilgiler sağlaması bakımından her geçen gün artan bir önem kazanmaktadır. Beyin daha önce oldukça statik bir organ olarak bilinmekteydi. Ancak günümüzde beyin sistemini oluşturan düzeninin deneyimlerle sürekli değiştiği bilinmektedir. Bu değişimler beyin plastisitesi (brain platicity) olarak tanımlanmaktadır. Beynin yapısını oluşturan sinirler arasındaki sinirsel iletim değişiminde etkili olan faktörlerden biri de kişinin gerek anne karnında gerek doğum sonrası yaşantısındaki deneyimleridir. Erken yaşlarda karşılaşılan bir deneyimin etkisi, ileri yaşlarda edinilen aynı deneyimin etkisinden farklıık göstermektedir. Ancak hala bunun altında yatan sebepler açıklanamamıştır (Kolb, Gibb ve Robinson, 2003).

Sinir sistemleri nöron ve glia hücrelerinden meydana gelmektedir. Sinir sistemleri nöral iletişim ağı şeklinde organize olup, bilgiyi işleyebilmektedir (Sadava vd., 2011, s.944). Beynimizdeki nöronlar, içten ve dıştan gelen uyarıların (impuls) şiddetine, tekrarına, düzeyine ve durumuna dayalı olarak bağlantı kurmaktadır. Bu nöronlar arası bağlantılar, uyarının vücudun ihtiyaçlarına ve beynin beklentilerine göre anlamlı olup olmamasına, gerekli ya da gereksiz olmasına göre ya zayıflayarak koparılıp atılmakta ya da çok güçlü ise beyine kazınarak yeni bağlantıların oluşmasına imkân sağlamaktadır (Duman, 2009, s.65). Sinirsel seviyede olan şey, muhtemelen bilişsel düzeyde gerçekleşir. Gerçek dönüşüm, beyin yapısında depolanan kavramlara karşıık gelen sinir ağlarının yeniden bağlantılar kurmasını gerektirir. Dolayısıyla, kavramsal değişim, zihinsel çalışma ve enerjinin harcanması ile birlikte güçlü ve sürekli çaba gerektirir (Liu ve Chiang, 2014). Sonuç olarak deneyim yaşa bağlı olarak beyni etkilemektedir. Gerek anne karnında gerek daha sonra meydana gelen bazı uzun süreli etkiler kişinin davranışını ve beyin yapısını etkilemektedir (Kolb, Gibb ve Robinson, 2003).

Modern nöroanatomi her bir yarımküreyi dört temel bölüme yani loba ayırmaktadır. Frontal (alnın hemen arkası, beynin ön bölümü), parietal (üstte, beynin arkaya doğru olan bölümü), temporal (yanlarda, şakakların altındaki bölüm) ve oksipital (beynin en arka bölümü) (Smith ve Kosslyn, s.20). Edelenbosh vd. (2015) son yıllardaki beyin tabanlı öğrenmeyle ilgili gelişmelere de dikkat çekerek bilim ve eğitim uygulamaları arasındaki sınıra dikkat çekmektedir. Beynin açıkça eğitimin ilgi alanında yer aldığını ve uygulamalarla birlikte bilimsel bilgiyle birleştirilmesine yönelik adımlar atıldığını belirtmektedir. Sağ ve sol hemisferlerler arasındaki ilişkinin araştırıldığı günümüzde beynin dört çeyrekle ifade edildiği Ned Herrmann'ın bütünsel beyin modeli, nöroanatomiye paralel olmakla birlikte düşünme hakkında daha ayrıntılı bilgi sağlaması açısından beyin ve eğitim ilişkisinin kurulduğu çalışmalarda tercih edilen bir model olarak karşımıza çıkmaktadır (Bawaneh vd., 2012; De Boer ve Steyn, 1999) Herrmann'ın Bütünsel beyin modeli EEG (elektroselografi) kullanılarak elde edilen çalışmaların ürünü olarak ortaya çıkmış, bu çalışmalarından elde edilen bilgiler uzmanlaşmış düşünme için bireyin göreceli tercihlerini ölçmeye izin veren insan beyninin uzmanlaşmış yapısına benzetmeye çalışılan metaforik bir model oluşturmak için kullanılmıştı. Bu metafor beynin dört çeyrek modelinin bir ya da daha fazla bölgesinin baskınlığıydı. Herrmann, oluşturulan metaforik bütünsel beyin modelinin düşünme biçimlerini ve tercihlerini belirleme için kullanışlı ve geçerli bir kaynak olarak öne sürmüştür (Herrmann 2003, s.31). Herrmann dört çeyrekli beyin modelini oluşturmasında MacLean'in analizi ve Sperry'nin çalışmasından yararlanmıştı. Serebral korteksin (üst beynin) iki bölümünü temsil eden dört düşünme biçimini Roger Sperry'nin sağ ve sol beyin teorisi, limbik sistemin iki bölümünü Dr. Paul MacLean'in Triune beyin teorisi ile birleştirerek bütünsel düşünen beyni temsil eden dört çeyrek modelini oluşturmuştur (Herrmann, 2003, s.28). 


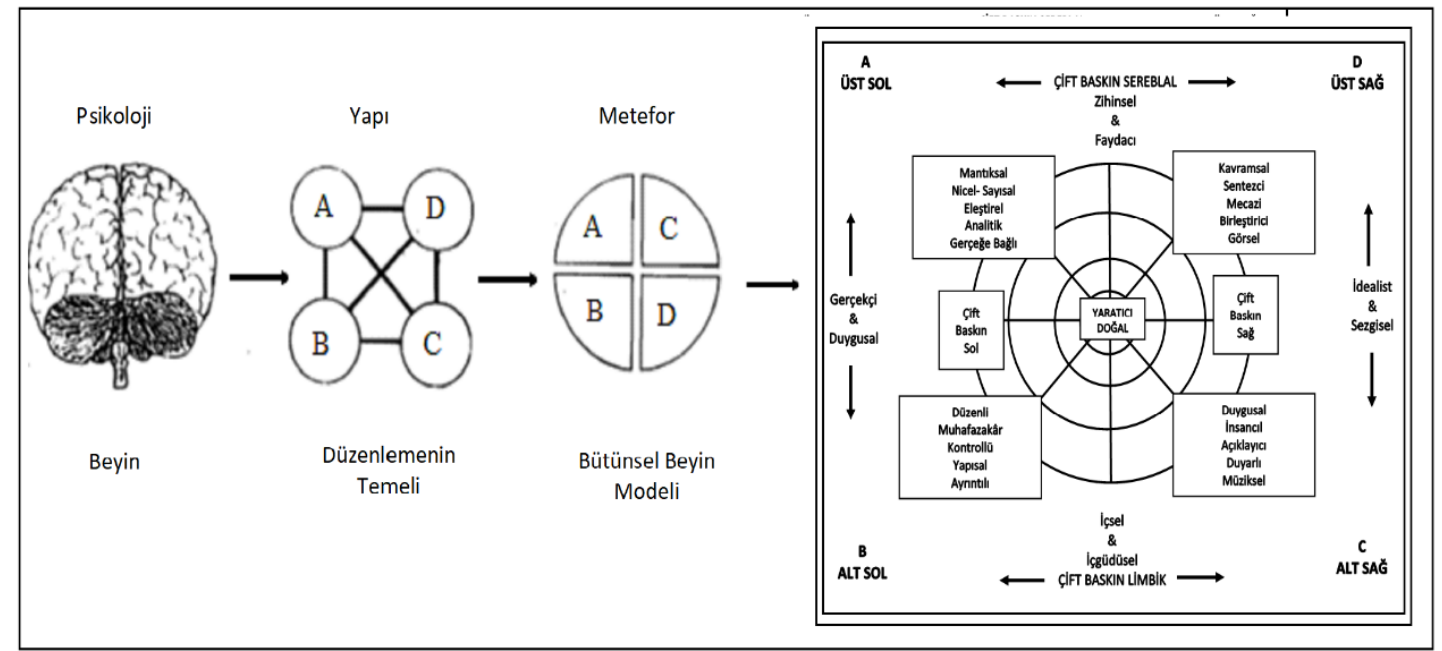

Şekil 1.Ned Herrmann'ın Bütünsel Beyin Modeli'nin yapılanması (De Boer ve Steyn, 1999 ; Herrmann, 2003, s.37 çalışmalarından derlenmiştir).

Şekil 1'de görüldüğü gibi Ned Herrmann'ın geliştirdiği modele göre beyin sol-üst (A), sol-alt (B), sağ-alt (C) ve sağ-üst (D) olmak üzere dört çeyreğe ayrılmıştır. A çeyreğini analiz eden, mantıksal düşünen, sayısal işlemler yapan; B çeyreğini organize eden, yaklaşımları planlayan ayrıntılı olarak gözden geçiren; $C$ çeyreğini kişiselleştiren, insan ilişkileri kuvvetli, sezgisel ve açıklayıcı; D çeyreğini hayal gücü kuvvetli, geniş açılı düşünen ve kavramsallaştıran olarak tanımlanmıştır (Herrmann, 2003, s.19). Beyin çeyreklerini destekleyen diğer bir araştırmacı Kolb geliştirdiği öğrenme döngüsünü dört çeyrek modelle ilişkilendirmiştir. Kolb’un öğrenme döngüsünde her bir çeyrekte bir öğrenme meydana gelmektedir. Her bir beyin çeyreği yapılandırıcılığı içeren aktivitelerle de ilgidir. Sol limbik çeyrek mantıksal aktiviteleri göstermektedir. Hissetme ve sorgulamayla yeni bilgilerin deneyimlenmesiyle ilgilidir. Gözlemlerin ve geri bildirimin olduğu sol kortikal çeyrek eleştirel düşünme, sağ kortikal çeyrek soyut analiz için olup etraflıca düşünmeye, sağ limbik çeyrekteki aktiviteler ise problem çözme ve harekete geçmekle ilgilidir (Eagleton ve Muller, 2011). Herrmann'ın üzerinde durduğu diğer bir konu ise baskınlık kavramıdır. Bütünsel beyin teknolojisini düşünen beyin fizyolojisi üzerine kuran Herrmann, düşünmek için beynin, bir beyin zarına (korteks) sahip olması gerektiğini belirtir. Çünkü sinirsel, birlikte çalışan aktivite sadece beyin zarında gerçekleşmektedir. Herrmann açıklamasında beynin tamamında düşünmeyi sağlayan dört bölüm olduğunu bunların serebral yarım kürenin iki bölmesi ve limbik sistemin iki bölmesi olup birbirinden oldukça farklı olduğunu belirtmektedir. Hayat deneyimleri süresince partnerin bir yapısı diğerine baskın gelirse, bu baskınlık derecesinin kişinin zihinsel tercihlerine bir delil olacağını belirtmektedir (Herrmann, 2003, s.30).

Gelişen ve hızla değişen dünyamızda ezberlemeye çalışan değil, nasıl öğrendiğini bilen, öğrendiklerini anlamlandırabilen bireylere olan ihtiyaç giderek artmaktadır (Duman, 2009, s. 17). Bu yönde öğrenmeyi kolaylaştırmak amacıyla beyin ile ilgili çalışmaların son zamanlarda eğitim alanıyla daha fazla ilişkilendirildiği görülmektedir (Anderson, 2009; Battro vd., 2013; D'Amato ve Wang, 2015; Degen, 2014; Özgen vd., 2011; Şenel-Çoruhlu, 2016). Derslerde sürekli yapılan ön bilgilerin tekrarlanması ile nöral ağların harekete geçirilmesi, konuların günlük hayatla ilişkilendirilmesi bilgilerin uzamsal belleğe kaydedilmesi ve bu nedenle daha sonra bu bilgilerin daha kolay hatırlanması gibi beyin araştırmalarının birçok bulgusu eğitim ve öğretim faaliyetlerini planlamadan değerlendirmeye kadar birçok açıdan etkilemektedir (AvcıErduran ve Yağbasan, 2008; Keleş ve Çepni 2006). Ülkemizde beyin ve eğitim arasındaki sınırı 
kaldırmaya çalışan çalışmalarda Herrmnann'ın çalışmasından Özden (2014) tarafından uyarlanan ve beyin baskınlık aracı doktora tezlerinden yüksek lisans tezlerine kadar geçerli bir araç olarak tercih edilmektedir. Bu çalışmalar ile öğrencilerin baskın olan beyin bölgesinin belirlenmesi, baskın beyin bölgelerinin değişik faktörlerle olan ilişkisinin ortaya koyulmaya çalışıldığı ve baskın beyin bölgelerine yönelik ders planlaması ile beyin- eğitim ilişkisinin kullanıldığı görülmektedir (Akgül, 2010; Bağçeci vd., 2009; Özgen vd., 2011; Demirel ve Tikici, 2010; Şenel Çoruhlu vd., 2016; Tokcan; 2007). Bütünsel beyin modelini temel alan araştırmalarda beyin çeyreklerinin öğrenme stilleri (Özgen vd., 2011), akademik başarı (Bağçeci vd. 2009) ve motivasyonla (Bawaneh vd., 2012) da ilişkili olduğunu ortaya koymaktadır. Her kişinin beyin yapısı farklı bir algılama ve öğrenme sisteminde yaratılmış olup beynin nasıl öğrendiğinin bilinmesi insanların öğrenmelerini kolaylaştırarak, anlamayı uzun soluklu ve güçlü kılmaktadır (Polat, 2014). Tokcan (2007) eğitimcilerin öğrencilerinin öğrenme çeyreklerinden haberdar olmaları gerektiğini ve bu dört çeyreği geliştirmesi ve bütünleştirmesi gerektiğini vurgulamaktadır. Herrmann (2003, s.57) zayıf olan veya az tercih edilen bir beyin çeyreğinin yapılacak olan işin kalitesini düşüreceğini belirtmektedir. Özden (2014, s.77) öğrenmenin nasıl gerçekleştiğini anlamak ve öğretimi kolaylaştırmak için beynin temel bölümlerine ilişkin bilgi sahibi olmak gerektiğini belirtmektedir. Bu amaçla Fen ve Matematik öğretmen adaylarının baskın olmayan beyin bölgelerinin tespit edilmesi araştırmanın temel hedefini oluşturmaktadır. Bu doğrultuda aşağıdaki sorulara cevap aranmıştır.

Fen Bilgisi öğretmen adaylarının baskın olarak kullanmadıkları beyin bölgesi nedir?

Matematik öğretmen adaylarının baskın olarak kullanmadıkları beyin bölgesi nedir?

Fen ve Matematik öğretmen adaylarının kullandıkları beyin bölgeleri bakımından anlamlı fark var mıdır?

\section{YÖNTEM}

Bu araştırma tarama modelindedir. Tarama modelleri, geçmişte ya da halen var olan bir durumu var olduğu şekliyle betimlemeyi amaçlamaktadır (Karasar, 1998, s.77). Verilerden gelen puanlarla nicel veri analizleri yapılmıştır. Öğretmen adaylarının bütünsel beyin yaklaşımını ortaya koymak için bu modele başvurulmuştur.

\section{1. Çalışma Grubu}

Bu araştırma 2016-2017 eğitim öğretim yılı bahar döneminde Türkiye'nin batı bölgesindeki bir devlet üniversitesinin fen bilgisi ve matematik öğretmenliği lisans programı altıncı yarıyıl öğretmen adayları ile yürütülmüştür. Çalışma grubunun seçilmesinde amaçlı örnekleme yöntemleri içinde yer alan kolay ulaşılabilir örnekleme tekniği kullanılmıştır. Kolay ulaşılabilir örneklem, yakın ve erişilmesi kolay olan durumun seçilmesidir (Patton, 2014, s.243; Merriam, 2013 s.76). Rastgele doldurulduğu tespit edilen ya da boş bırakılan formlar çıkarıldıktan sonra toplam 133 formun değerlendirmesi yapılmıştır. Çalışma grubunu oluşturan Fen bilgisi öğretmenliğinde eğitim gören öğrencilerin 62'si $(\% 88,6)$ kız, sekizi $(\% 11,4)$ erkektir. Matematik öğretmenliğinde eğitim gören öğrencilerin 58'i $(\% 92,1)$ kız, beşi $(\% 7,9)$ erkektir.

\subsection{Veri Toplama Aracı}

Araştırma verileri Herrmann'ın Dört Çeyrekli Beyin Baskınlık Aracı'nın Özden (2014) tarafından uyarlanmış hali ile toplanmıştır. Araç altı bölümden oluşmuştur. Her bölümde dörder soru yer almaktadır. Aracın değerlendirilmesinde, birinci soruların toplamı D (Bütüncül), ikinci soruların toplamı C (Duygusal), üçüncü soruların toplamı B (Analitik) ve dördüncü soruların toplamı ise A (Mantıksal) çeyreğinin baskınlık derecesini ölçmektedir. Böylece her çeyreğe ait puan elde edilmektedir. Daha sonra hangi puan yüksek ise o çeyreğin baskınlığı hakkında bilgi sağlanmış olmaktadır. 


\subsection{Verilerin Analizi}

Bu araştırmada beyin baskınlık aracından elde edilen puanlar iki aşamada değerlendirilerek baskın beyin bölgeleri tespit edilmeye çalışılmıştır. İlk aşamada öğrencilerin $A, B, C$ ve $D$ çeyreklerinden aldıkları en yüksek puanları dikkate alınarak beyin bölgelerine göre gruplandırıımıştır. Bunun sonucunda önce $A$ puanı, $B$ puanı, $C$ puanı, $D$ puanı, $A B$ puanı, $A C$ puanı, $A D$ puanı, $B C$ puanı, $B D$ puanı, $C D$ puanı ve $A B C D$ puanı olarak sınıflandırılmıştır. Üç beyin çeyreğinden alınan puanın aynı ve yüksek olması durumunda düşük olan puanı temsil eden çeyrek eksi sembolü (-) ile gösterilerek belirtilmiştir. Örneğin (-A), o öğrencinin A çeyreği dışındaki puanlarının yüksek ve aynı olduğunu göstermektedir. Bu aşama ile öğrencilerin baskın olan bölgelerinin frekansları hesaplanması hedeflenmiştir.

íkinci aşamada beyin bölgelerindeki yığılımı bulmak amacıyla bu frekanslarından yararlanarak kümülatif frekans hesaplaması yapılmıştır. Hesaplama sırasında beynin sol lobunu oluşturan $A B$, sağ lobunu oluşturan $C D$, ön lobunu oluşturan $A D$, ve arka lobu oluşturan $B C$ bir sınıf kabul edilmiş ve bu sınıfta yer alan bireylerin ilk aşamada elde edilen frekansları aralık kabul edilerek kümülatif frekans hesaplaması yapılmıştır. Hesaplamalar şu şekilde yapılmaktadır; $A B$ (sol lob) bölge kümülatif frekans hesaplaması = $A+B+A B$ frekansları toplamı, $C D$ (sağ lob) bölge kümülatif frekans hesaplaması $=C+D+C D$ frekansları toplamı, $A D$ (serebral) bölge kümülatif frekans hesaplaması = A+D+AD frekansları toplamı, BC (limbik) bölge kümülatif frekans hesaplaması $B+C+B C$ frekansları toplamı olarak bulunmaktadır. Elde edilen bulgular tanımlayıcı istatistik olarak sunulmuştur.

Verilerin betimsel analizinde önce fen bilgisi ve matematik öğretmen adaylarındaki beyin çeyreklerinden elde edilen puanların normal dağııım gösterip göstermediğini belirlemek amacıyla Kolmogorov-Smirnov testi yapılmıştır. Test sonucunda fen bilgisi öğretmen adaylarında $D$ çeyreği puanlarının normal dağılımdan farklılığı anlamlı bulunmamıştır $\left(z_{D}=0.07\right.$, $p>0,05)$. A çeyreği, $B$ çeyreği ve $C$ çeyreği puanları ise normal dağılımdan anlamlı olarak farklı bulunmuştur $\left(z_{A}=0.01, z_{B}=0.46\right.$ ve $\left.z_{C}=0.021\right)$. Matematik öğretmen adaylarından elde edilen puanların testi sonucunda $C$ ve $D$ çeyreği grubunun normal dağılımdan farklılığı anlamlı bulunmamıştır $\left(z_{C}=0.200\right.$ ve $\left.z_{D}=0.177, p>0.05\right)$. A çeyreği, $B$ çeyreği puanları ise normal dağılımdan anlamlı olarak farklı bulunmuştur $\left(z_{A}=0.016, z_{B}=0.001, p<0.05\right)$. Elde edilen sonuçlar doğrultusunda fen bilgisi ve matematik öğretmen adayları arasında beyin çeyreklerinden aldıkları puanlar bakımında fark olup olmadığını belirlemek amacıyla bağımsız grup t-testi ve non-parametrik Mann Whitney-U Testi uygulanmıştır.

\section{BULGULAR}

Verilerin analizi sonucu problemlere ilişkin elde edilen bulgular aşağıda tablolar halinde sunulmuştur.

İlk olarak Fen bilgisi ve Matematik öğretmen adaylarının beyin baskınlık aracında beyin çeyreklerinden aldıkları puanlara göre hangi bölgenin daha baskın olduğu tespit edilmeye çalışıımıştır. Bu amaçla yapılan tanımsal analiz sonuçları Tablo 1'de sunulmuştur.

Tablo 1

Öğretmen Adaylarının Beyin Baskınlık Puanlarının Frekans Tablosu

\begin{tabular}{lcccc}
\hline \multicolumn{1}{c}{ Beyin bölgeleri } & $\mathrm{f}$ & $\%$ & $\mathrm{f}$ & Matematik \\
\hline A (üst sol) & 1 & 1.4 & 2 & 3.2 \\
B (alt sol) & 12 & 17.1 & 13 & 20.6 \\
C (alt sağ) & 36 & 51.4 & 35 & 55.6 \\
D (üst sağ) & 7 & 10.0 & 6 & 9.5
\end{tabular}




\begin{tabular}{lcccc} 
AB (sol lob) & 1 & 1.4 & - & - \\
CD (sağ lob) & 4 & 5.7 & 2 & 3.2 \\
AD (serebral) & - & - & - & - \\
BC (limbik) & 3 & 4.3 & 4 & 6.3 \\
AC & 4 & 5.7 & - & \\
BD & 1 & 1.4 & 1 & 1.6 \\
$-A$ & - & - & - & - \\
$-B$ & - & - & - & - \\
$-C$ & - & - & - & - \\
$-D$ & 1 & 1.4 & - & - \\
ABCD & - & - & - & - \\
\hline Toplam & 70 & 100 & 63 & 100 \\
\hline
\end{tabular}

Tablo 1'e göre öğretmen adaylarının puanları baskın beyin çeyrekleri bakımından en az $A$ ve $D$ çeyreklerinde olduğu tespit edilmiştir $\left(f_{\text {fen }}=\% 1.4, f_{\text {matematik }}=\% 3.2\right)$. En baskın çeyrek ise hem fen hem de matematik öğretmen adayları için C (alt sağ) beyin çeyreğinde olduğu görülmektedir $\left(\mathrm{f}_{\mathrm{fen}}=51.4, \mathrm{f}_{\text {matematik }}=55.6\right)$.

Öğretmen adaylarının kullandıkları beyin bölgelerindeki yığılımı tespit amacıyla kümülatif frekans tablosundan yararlanılmıştır. Hesaplama sırasında beynin sol lob bölgesini oluşturan $A B$, sağ lob bölgesini oluşturan $C D$, serebral bölgeyi oluşturan $A D$ ve limbik bölgeyi oluşturan $B C$ bir sınıf kabul edilmiş ve bu sınıfta yer alan bireylerin Tablo 1'deki frekansları aralık kabul edilerek bulunan kümülatif frekans sonuçları Tablo 2'de verilmiştir.

Tablo 2

Fen ve Matematik Öğretmen Aday Sayısının Beyin Bölgelerine Göre Gruplanmış Dağılımı

\begin{tabular}{|c|c|c|c|c|c|c|}
\hline \multirow[t]{2}{*}{ Beyin bölgeleri } & \multicolumn{3}{|c|}{ Fen } & \multicolumn{3}{|c|}{ Matematik } \\
\hline & $f$ & Kümülatif f & Kümülatif \% & $f$ & Kümülatif f & Kümülatif \% \\
\hline$A$ & 1 & 1 & 1.4 & 2 & 2 & 3.2 \\
\hline B & 12 & 13 & 18.5 & 13 & 15 & 23.6 \\
\hline$A B$ & 1 & 14 & 19.9 & - & 15 & 23.6 \\
\hline $\begin{array}{l}\text { Toplam AB (sol lob) } \\
\text { bölgesi }\end{array}$ & & 14 & 19.9 & & 15 & 23.6 \\
\hline $\mathrm{C}$ & 36 & 36 & 51.4 & 35 & 35 & 55.6 \\
\hline D & 7 & 43 & 61.4 & 6 & 41 & 65.1 \\
\hline$C D$ & 4 & 47 & 67.1 & 2 & 43 & 68.3 \\
\hline $\begin{array}{l}\text { Toplam CD (sağ lob) } \\
\text { bölgesi }\end{array}$ & & 47 & 67.1 & & 43 & 68.3 \\
\hline$A$ & 1 & 1 & 1.4 & 2 & 2 & 3,2 \\
\hline D & 7 & 8 & 11.4 & 6 & 8 & 12.7 \\
\hline$A D$ & - & 8 & 11.4 & - & 8 & 12.7 \\
\hline $\begin{array}{l}\text { Toplam AD (serebral) } \\
\text { bölgesi }\end{array}$ & & 8 & 11.4 & & 8 & 12.7 \\
\hline$B$ & 12 & 12 & 17.1 & 13 & 13 & 20.6 \\
\hline C & 36 & 48 & 68.5 & 35 & 48 & 76.2 \\
\hline$B C$ & 3 & 51 & 72.8 & 4 & 52 & 82.5 \\
\hline $\begin{array}{l}\text { Toplam BC (limbik) } \\
\text { bölgesi }\end{array}$ & & 51 & 72.8 & & 52 & 82.5 \\
\hline
\end{tabular}


Tablo 2'ye göre fen ve matematik öğretmen adaylarının en az kullanılan bölgenin hem fen hem de matematik öğretmen adaylarında $A D$ (serebral) bölgesi (Kümülatif $f_{\text {fen }}=\% 11.4$, Kümülatif $f_{\text {matematik }}=\% 12.7$ ) ve $A B$ (sol lob) bölgesi (Kümülatif $f_{\text {fen }}=\% 19.9$, Kümülatif $f_{\text {matematik }}=\% 23.6$ ) olduğu görülmektedir. Diğer taraftan $B C$ (limbik) bölgesi (Kümülatif $f_{\text {fen }}=\% 72.8$, Kümülatif $f_{\text {matematik }}=\% 82.5$ ) ve $C D$ (sağ lob) bölgesini (Kümülatif $f_{\text {fen }}=\% 67.1$, Kümülatif $\mathrm{f}_{\text {matematik }}=\% 68.3$ ) daha baskın olarak kullandıkları görülmektedir.

Öğrencilerin beyin baskınlık aracı puanlarının betimsel analizi yapılarak beyin çeyreklerinden aldıkları ortalama puanları hesaplanmıştır. Elde edilen bulgular Tablo 3'de sunulmuştur.

Tablo 3

Öğretmen Adaylarının Beyin Baskınlık Puanlarının Betimsel Analiz Sonuçları

\begin{tabular}{cllllll}
\hline $\begin{array}{c}\text { Beyin } \\
\text { çeyreği }\end{array}$ & Bölüm & $\mathbf{N}$ & $\overline{\mathbf{X}}$ & SD & Minumum & Maksimum \\
\hline A & Fen & 70 & 20.24 & 3.25 & 14 & 27 \\
& Matematik & 63 & 20.00 & 3.01 & 16 & 28 \\
B & Fen & 70 & 21.67 & 3.54 & 10 & 27 \\
& Matematik & 63 & 21.86 & 3.56 & 15 & 30 \\
C & Fen & 70 & 24.04 & 2.60 & 18 & 30 \\
& Matematik & 63 & 24.25 & 3.15 & 12 & 30 \\
D & Fen & 70 & 21.57 & 2.44 & 16 & 27 \\
& Matematik & 63 & 21.49 & 2.57 & 15 & 27 \\
\hline
\end{tabular}

Beyin baskınlık aracından alınan puanların betimsel analiz sonuçlarına göre fen bilgisi öğretmen adaylarının beynin $C$ çeyreği ortalamasının $(M=24.04)$ en yüksek, A çeyreği ortalamasının ( $M=20.24)$ en düşük olduğu görülmektedir. Beyin baskınlık analizinin betimsel analiz sonuçlarına göre matematik öğretmen adaylarının beynin C çeyreği ortalamasının $(M=24.25)$ en yüksek, $A$ çeyreği ortalamasının $(M=20.00)$ en düşük olduğu görülmektedir. $B u$ sonuçlar Tablo 1'de elde edilen sonuçlar ile uyumludur.

Fen bilgisi ve matematik öğretmen adayları arasında beyin çeyreklerinden aldıkları puanlar bakımından fark olup olmadığını belirlemek amacıyla bağımsız grup t-testi ve nonparametrik Mann Whitney-U Testi uygulanmıştır. Bu doğrultuda yapılan analizler aşağıda sunulmuştur.

Fen bilgisi ve matematik öğretmenliği öğretmen adaylarının normal dağılım gösteren $D$ çeyreği puanlarının anlamlı bir farklılık gösterip göstermediğini belirlemek amacıyla bağımsız grup t-testi uygulanmıştır. Elde edilen sonuçlar Tablo 4'de sunulmuştur.

Tablo 4.

Fen ve Matematik Öğretmen Adaylarının D Çeyreği Puanları Arasında Fark Olup Olmadığını Belirlemek Üzere Yapılan Bağımsız Grup t- Testi Sonuçları

\begin{tabular}{|c|c|c|c|c|c|c|c|c|}
\hline \multirow{2}{*}{$\begin{array}{l}\text { Beyin } \\
\text { çeyreği }\end{array}$} & \multirow{2}{*}{ Bölüm } & \multirow{2}{*}{$\mathbf{N}$} & \multirow{2}{*}{$\overline{\mathbf{X}}$} & \multirow{2}{*}{ ss } & \multirow{2}{*}{$\mathrm{Sh}_{\mathrm{x}}$} & \multicolumn{3}{|c|}{ t-testi } \\
\hline & & & & & & $\mathbf{t}$ & Sd & $p$ \\
\hline \multirow{2}{*}{ D } & Fen & 70 & 21.57 & 2.43508 & 0.29105 & \multirow{2}{*}{0.182} & \multirow{2}{*}{127.627} & \multirow{2}{*}{0.856} \\
\hline & Matematik & 63 & 21.49 & 2.57703 & 0.32467 & & & \\
\hline
\end{tabular}

Tablo 4'de yer alan t-testi sonuçlarına göre Fen ve Matematik öğretmen adayları arasında $D$ çeyrek puanları bakımından anlamlı bir fark bulunmamıştır $\left(t_{0.05}=0.856, p>0.05\right)$.

Fen Bilgisi öğretmenliği ve Matematik öğretmenliği öğretmen adaylarının normal dağılım göstermeyen $A, B$ ve $C$ çeyreği puanları arasında anlamlı bir fark olup olmadığını 
belirlemek amacıyla non-parametrik Mann-Whitney-U testi uygulanmıştır. Elde edilen sonuçlar Tablo 5'de sunulmuştur.

Tablo 5

Fen ve Matematik Öğretmen Adaylarının A, B ve C Çeyreği Puanları Arasında Fark Olup Olmadığını Belirlemek Üzere Yapılan Mann Whitney-U Testi Sonuçları

\begin{tabular}{|c|c|c|c|c|c|c|c|}
\hline $\begin{array}{l}\text { Beyin } \\
\text { çeyreği }\end{array}$ & Bölüm & $\mathbf{N}$ & $\bar{x}_{\text {sira }}$ & $\sum_{s i r a}$ & U & $\mathbf{z}$ & p \\
\hline \multirow{3}{*}{ A } & Fen & 70 & 68.43 & 4790.00 & \multirow{3}{*}{2105.00} & \multirow{3}{*}{-0.453} & \multirow{3}{*}{0.651} \\
\hline & Matematik & 63 & 65.41 & 4121.00 & & & \\
\hline & Toplam & 133 & & & & & \\
\hline \multirow{3}{*}{ B } & Fen & 70 & 66.47 & 4653.00 & \multirow{3}{*}{2168.00} & \multirow{3}{*}{-0.168} & \multirow{3}{*}{0.867} \\
\hline & Matematik & 63 & 67.59 & 4258.00 & & & \\
\hline & Toplam & & & & & & \\
\hline \multirow{3}{*}{ C } & Fen & 70 & 64.16 & 4491.00 & \multirow{3}{*}{2006.00} & \multirow{3}{*}{-0.903} & \multirow{3}{*}{0.367} \\
\hline & Matematik & 63 & 70.16 & 4420.00 & & & \\
\hline & Toplam & 133 & & & & & \\
\hline
\end{tabular}

Tablo 5'de elde edilen sonuçlara göre fen ve matematik öğretmen adayları arasında beynin $A$ çeyreği, $B$ çeyreği ve $C$ çeyreği puanları bakımından fark bulunmamıştır $\left(U_{A}=2105.00\right.$; $\left.p=0.651, U_{B}=2168.00 ; p=0.867, U_{C}=2006.00 ; p=0.367, p<0.05\right)$.

\section{SONUÇ, TARTIŞMA VE ÖNERILER}

Bu çalışmada, fen ve matematik eğitimi alan öğretmen adaylarının baskın olmayan beyin bölgelerinin tespit edilmesi amaçlanmıştır. Bu amaçla yapılan tanımsal ve betimsel analiz sonucunda öğretmen adaylarının en zayıf olan beyin çeyreklerinin $A$ ve $D$ olduğu tespit edilmiştir. A çeyreği daha çok analitik problem çözme, mantık ve muhakeme gibi zihinsel işlevlerle ilişkilendirilmektedir (Özden, 2014, s.85). Mantıksal ve analitik düşünme ile ilgili olan A çeyreğinin baskın olduğu durumda, gerçekler olmadan hiçbir kararın alınmadığını, mantığın duygulardan daha baskın olduğu belirtilmektedir (Herrmann, 2003, s.38). Araştırma bulgularına göre baskın olmayan diğer beyin çeyreğinin D olduğu tespit edilmiştir. Bu çeyreği baskın olan kişilerin daha çok sanat, geometri ve tasarımla ilgili oldukları belirtilmektedir (Özden, 2014, s.96). Beynin çalışmasını arttırarak bağlantı sayısını değiştirmek böylece de beyin kapasitesini değiştirmenin mümkün olduğu bilinmektedir (Duman 2009, s.75). Akgül (2010) Bloom Taksonomisi'nde yer alan bilişsel basamakların beyin bölgelerine göre dağılımını gösterdiği çalışmasında A çeyreğinin bilgi, kavrama, analiz, D çeyreğinin ise sentez ile ilişkili olduğunu ve eğitimde bu seviyedeki kazanımlara yer verilmesinin bu bölgelerin geliştirilmesinde etkili olacağını belirtmektedir.

Araştırma bulgularına göre öğretmen adaylarında en az tercih edilen bölgenin serebral bölgesi olduğu bulunmuştur. Frontal loblarla da ilişkili olan bu bölge genellikle davranışın veya düşüncenin sıralaması ve düzenlenmesinde rol oynar. Konuşmanın gerçekleşmesi frontal alanın temel işlevlerindendir. Frontal alanlar karar vermede de etkilidir (Smith ve Kosslyn, 2014, s.22). Beynin büyük bir bölümünü ilgilendiren frontal lobların akılcı insan davranışları için ayırt edici bir faktör gibi görünen en yüksek zihinsel işlevleri içerdiğine inanılmaktadır. Diğer önemli bir alan olan dil ve problem çözme ile ilgili olduğu bilinmektedir (D'Amato ve Wang, 2015). Özellikle ön frontal lob yürütücü işlem adı verilen, diğer işlemlerin çalışmasını değiştiren, belirli bir amaca ulaşmak adına zihinsel aktiviteyi kontrol eden süreçlere aracılık etmekte olup, seçici dikkat ve karar vermede etkilidir (Smith ve Kosslyn, 2014, s.281-285). Herrmann (2003, s.41) A ve $D$ çeyrekleri baskın olan bireyleri daha bilimsel olarak tanımlarken, $B$ ve $C$ çeyreklerini sosyal çalışmalardan hoşlanan bireyler olarak tanımlamaktadır. Bu durum öğretmen adaylarının 
bilimsel yönlerinin güçlendirilmesi gerektiği şeklinde yorumlanabilir. Eagleton ve Muller (2011) çalışmasında analitik düşünme ile ilgili A çeyreği eleştirel düşünme, geri bildirim ve gözlem, holistik düşünmeyle ilgili $D$ çeyreği ise soyut ve etraflıca düşünme ile ilgili aktivitelerle ilişkilendirmektedir.

Öğretmen adaylarında sol beyin bölgesinin daha az tercih edilen olduğu tespit edilmiştir. Beyin bütün olarak öğrenmekte olup, sağ ve sol yarım küre fonksiyonlarının birlikte kullanılması öğrenmede büyük önem taşımaktadır. (Erduran Avcı ve Yağbasan, 2008). Beyinlerinin sol yarı küresini kullanmayı tercih edenlerin okuyarak, sağ yarımküresini başat kullananların ise görerek ve deneyerek öğrenmekte olması gibi, bir yarının kullanımın artmasının diğer yarının kullanımını zorlaştırdığını belirtilmektedir. (Özden, 2014, s.78).

Araştırmanın diğer bir bulgusu olarak fen ve matematik öğretmen adaylarının beyin çeyrek ortalamaları arasında anlamlı bir farklılık bulunmamıştır. Diğer bir ifade ile fen bilgisi ve matematik öğretmen adaylarının en çok kullanılan beyin çeyreği ortalaması $C$ olarak tespit edilmiştir. Özden $(2014$, s.92) öğretmen ve eğitimcilerin kuvvetli olarak C çeyreğini gösterdiğini, A çeyreğinde ise daha çok avukat, mühendis, bilgisayar uzmanı, analizciler, teknisyenler, bankerler ve doktorların yer aldığını belirtmektedir. Bu sonucun, beynin plastik yapısını desteklediği ve eğitim fakültelerine giden öğrencilerde C çeyreğinin baskın hale geldiği düşünülebilir. Öğrenme beynimizi fiziksel olarak değiştirmekte olup, her yeni deneyim beyindeki nöronlar arasındaki bağlantıyı değiştirmektedir (Duman, 2009, s.67). Kapsamlı bir eğitimin beyin yapısını yetişkinken bile değiştirebileceği savunulmaktadır (Slavin, 2013, s.154).

Bu çalışmadan elde edilen bulgular doğrultusunda öğretmen adaylarının karar verme ve muhakemede etkili olan serebral bölgelerini aktif kılan eğitim uygulamalarının arttırılması gereği açıktır. Eğitimin amacı öğrencilerin beyinlerinin belli bir yarısını etkin kılarak diğer kısmını ihmal etmek değil beyni mümkün olan tüm yönleriyle dengeli bir şekilde geliştirmek olmalıdır.

\section{KAYNAKLAR}

Anderson, O. R. (2009). Neurocognitive theory and constructivism in science education: A review of neurobiological, cognitive and cultural perspectives. Brunei International Journal of Mathematics and Science Education, 1, 1-32.

Akgül, G. (2010). Illköğretim Türkçe (6,7,8 sınıflar) 2006 öğretim programında yer alan okuma, düzenleme, konuşma, yazma öğrenme alanlarındaki kazanımların bütünsel beyin modeline göre analiz edilmesi ve sınıflandırılması. (Yayımlanmamış Yüksek Lisans Tezi), Mustafa Kemal Üniversitesi, Hatay, Türkiye.

Avcı-Erduran D. ve Yağbasan, R. (2008). Beyin yarı kürelerinin baskın olarak kullanılmasına yönelik öğretim stratejileri. GÜ Gazi Eğitim Fakültesi Dergisi. 28(2), 1-17.

Bawaneh, A.K.A., Zain, A.N., Saleh, S. ve Abudllah, A.G.K. (2012). Using Herrmann whole brain teaching method to enhance students' motivation towards science learning. Türk Fen Eğitimi Dergisi. 9(3), 3-21.

Bağçeci, B., Kanadlı, S. ve Ünişen, A. (2009). Farklı beyin yarım küreleri baskın öğrencilerin Ingilizce akademik başarılarındaki farklıııkların incelenmesi. Adıyaman Üniversitesi Sosyal Bilimler Enstitüsü Dergisi, 2(3), 22-34.

Battro, A. M., Calero, C. I., Goldin, A. P., Holper, L., Pezzatti, L., Shalóm, D. E. ve Sigman, M. (2013). The cognitive neuroscience of the teacher-student interaction. Mind, Brain, and Education. 7(3), 177-181. 
D'Amato, R. C., ve Wang, Y. Y. (2015). Using a Brain-Based Approach to Collaborative Teaching and Learning with Asians. New Directions for Teaching and Learning. (143), 41-60.

De Boer, T., Steyn, T. (1999). Thinking style preferences of underprepared first year students in the natural sciences. South African Journal of Ethnology, 22(3), 97-102.

Degen, R. (2014). Brain-Based Learning: The neurological findings about the human brain that every teacher should know to be effective. Amity Global Business Review. 9, 15-23.

Duman,B. (2009). Neden beyin temelli öğrenme. Ankara: Pegem.

Demirel, E. T. ve Tikici, M. (2010). Üniversite Öğrencilerinin Girişimcilik Özelliklerinin Beyin Baskınlık Analizi Ile Değerlendirilmesi: İnönü Üniversitesi ii BF İşletme Bölümü Örneği. Elektronik Sosyal Bilimler Dergisi (http://www. esosder. com), 9(32), 221-253.

Edelenbosh, R., Kupper, F., Krabbendam, L. ve Broersa, J.E.W. (2015). Brain-based learning and educational neuroscience: Boundary work. Mind, Brain, and Education. 9(1), 40-49.

Eagleton, S. ve Muller, A. (2011). Development of a model for a whole brain learning of physiology. Adv. Physiol. Educ. 35:421-426.

Erduran-Avcı, D. ve Yağbasan, R. (2008). Beyin yarı kürelerinin baskın olarak kullanılmasına yönelik öğretim stratejileri. G.Ü. Gazi Eğitim Fakültesi Dergisi. 28(2), 1-17.

Herrmann, N. (2003). İş yaşamında bütünsel beyin. (Çev. Mehmet Öner) İstanbul: Hayat.

Keleş, E. ve Çepni, S.(2006). Beyin ve öğrenme. Türk Fen Eğitimi Dergisi. 3(2), 66-82.

Korkmaz, Ö. ve Mahiroğlu, A. (2007). Beyin, bellek ve öğrenme. Kastamonu Eğitim Dergisi. 15(1),93-104.

Kolb, B., Gibb, R. ve Robinson, T.E. (2003). Brain plasticity and behaviour. Current Directions in Psychological Science 12(1), 1-5. Do:10.1111/14678721.01210.

Liu C. ve Chiang W. (2014). Theory, method and practice of neuroscientific findings in science education. International Journal of Science and Mathematics Education. 12, 629-646.

Merriam, S. B. (2013). Nitel araştırma: Desen ve uygulama için bir rehber. (Çev. S. Turan). Ankara: Nobel. [Orijinal baskı 2009].

Onan, B. (2010). Beynin bilişsel işlevleri üzerine yapılan araştırmalar ve ana dili eğitimine yansımaları. Türklük Bilimi Araştırmaları. 27,521-561.

Özden, Y. (2014). Öğrenme ve öğretme. Ankara: Pegem.

Özgen, K., Tataroğlu, B., ve Alkan, H. (2011). An examination of brain dominance and learning styles of pre-service mathematics teachers. Procedia-Social and Behavioral Sciences. 15, 743-750.

Patton M. Q. (2014). Nitel araştırma ve değerlendirme yöntemleri. (Çev. M. Bütün ve S.B. Demir). Ankara: Pegem Akademi.

Polat, M. (2014). Beyin temelli öğrenmenin açılımı nedir? Eğitim ve Öğretim Araştırmaları Dergisi. 3(2), 265-274.

Sadava, D., Hillis, D.M., Craig Heller, H.ve Berenbaum, M.R. (2014). Yaşam: Biyoloji Bilimi. (Ed. E. Gündüz, ì. Türkan). Ankara: Palme Yayıncılık

Slavin, R., E. (2013). Eğitim Psikolojisi. (Çev. Galip Yüksel). Ankara: Nobel Yayıncılık. 
Smith, E. ve Kosslyn, S. M. (2014). Bilişsel Psikoloji. (Çev. Ed. Muzaffer Şahin). Ankara: Nobel Yayıncilık.

Şenel-Çoruhlu, T., Er-Nas, S. ve Keleş, E. (2016). Beyin temelli öğrenme yaklaşımına dayalı web destekli öğretim materyalinin etkinliğinin değerlendirilmesi: Işık ve ses ünitesi. Amasya Üniversitesi Eğitim Fakültesi Dergisi. 5(1), 104-132.

Tokcan, H. (2007). Sosyal bilgiler öğretiminde bütünsel beyin yaklaşımı ile modellendirilmiş etkinliklerin akademik başarı ve tutumlar üzerine etkisi. (Yayınlanmamış Doktora Tezi). Gazi Üniversitesi, Ankara, Türkiye. 


\section{SUMMARY}

Recent developments in brain-based learning highlight the boundaries between science and education practices (Edelenbosh vd., 2015). There is a growing awareness that the brain is clearly involved in the field of education and that scientific knowledge is combined with practical applications. It seems that studies related to the brain have recently been more related to the field of education in order to facilitate learning in this field (Anderson, 2009; Battro et al., 2013; D'Amato and Wang, 2015; Degen, 2014; Özgen et al., 2011). For this purpose, determining non-dominant brain regions of prospective science and mathematics teachers constitutes the main objective of the research. The following questions have been answered in this direction.

What are the brain non-dominance profiles of prospective science teachers?

What are the brain non-dominance profiles of prospective mathematics teachers?

Is there a significant difference in terms of the brain regions of prospective science and mathematics teachers?

The survey method was used in the research. The participants of this study were 133 prospective teachers (70 science and 63 mathematics) studying in the spring semester of 2016-2017 education year in Turkey. The research data were collected by adapting Hermann's Four-Quadrant Brain Dominance Instrument adapted from Ozden (2014).

In this study, A (logical), B (analytic), C (emotional) and D (holistic) scores obtained from a brain dominance instrument were evaluated in two steps and the instrument attempted to determine dominant brain regions. In the first step, students are grouped according to their brain regions, taking into account the highest scores they receive from $A, B, C$ and $D$ quarters. As a result, they were classified as $A$ score, $B$ score, $C$ score, $D$ score, $A B$ score, $A C$ score, $A D$ score, $B C$ score, BD score, CD score and $A B C D$ score. If the scores from three brain quadrants are the same and high, they are indicated by a low score in the quarter with symbol (-). For example, (-A) indicates that the scores for that student are high and the same in the other quadrants, except for A quadrant score. With this step, it is aimed to calculate the frequencies of the dominant regions of the students. In the second stage, the cumulative frequency calculation was performed by using these frequencies to find the cluster in the brain regions. In calculation process, the cumulative frequency calculation was performed by determining $A B$, which constitutes the left lobe of the brain, $C D$ which forms the right lobe region, $A D$ which forms the cereblal region, and $B C$, which forms the limbic region was considered to be a class. Cumulative frequency calculations were made by taking the frequencies obtained in the first stage of the individuals included in this class as intervals. Calculations were made in the following way; cumulative frequency calculation of $A B$ (left lobe) region $=$ Sum of $A+B+A B$ frequencies, cumulative frequency calculation of $C D$ (right lobe) region = Sum of $C+D+C D$, cumulative frequency calculation of $A D$ (cereblal) region $=A+D+A D$, cumulative frequency calculation of $B C$ (limbic) region $=$ sum of frequencies of $B+C+B C$.

The Kolmogorv-Smirnov (K-S) tests were used in the quantitative dimension of the study in order to test normal data distribution. Independent Samples T-test was applied to the data which shows normal distribution and Mann- Whitney $U$ test was applied to the data which don't show normal distribution.

Prospective Science and Mathematics teachers have been identified as possessing the least dominant brain quartiles $A$ and $D$ according to their scores from brain quadrants through brain dominance. A quadrant is more often associated with mental functions such as analytical problem solving, reasoning (Özden, 2014, p.85). A quadrant that is related to logical and analytical thinking assumes no judgment is taken without facts, and logic is more dominant than emotions (Herrmann, 2003, p.38). It is stated that the people who are dominant in the quartet D quarter are mostly concerned with art, geometry and design (Özden, 2014, p.96). It is known that it is possible to change the brain capacity changing the number of connections through increasing brain functioning (Duman $2009, \mathrm{s.75}$ ). The dominant quadrant was found to be $C$ quadrant for the teachers. It was seen that the $A D$ (cerebral) region and the $A B$ (left lobe) region were the least used in both groups. The $A D$ region, which is associated with the frontal lobes, usually plays a role in the ordering and arrangement of behaviour or thinking. The realization of speech is the main function of the frontal region and this region is also influential in decision-making (Smith and Kosslyn, 2014, p.22). The most dominant regions of the brain were the $B C$ (limbic) region and the $C D$ (right lobe) region in the research groups. There was no statistically significant difference found between both groups of teachers' scores of $A, B, C$ and D 
quadrants. Akgül (2010) points out that the study of the distribution of cognitive steps in Bloom Taxonomy according to brain regions shows that $\mathrm{A}$ is related to knowledge, comprehension and analysis, $D$ is related to synthesis.

Eagleton and Muller (2011) associate analytical thinking with critical thinking, feedback and observation in A quadrant, and D quadrant regarding holistic thinking, with activities related to abstract and thorough thinking. Learning physically changes our brain, and every new experience changes the link between neurons in the brain (Duman, 2009, p.67). It is argued that comprehensive education can change the structure of the brain even in adulthood (Slavin, 2013, p.154). It is clear that in the outcomes of the findings obtained from this study, it is necessary for the prospective teachers to increase the AD regions which are effective in decision making and reasoning in active education programs. The aim of the training should be to improve the brain in all possible ways, to not neglect the inactive part by focusing on a certain half of the brain of the students. 